\title{
Discussion on the Key Properties of Fiberglass Tubing Used in Oilfield
}

\author{
Xuehua Cai, Houbu Li, Dongna Zhang, Guoquan Qi, Dongtao Qi \\ State Key Laboratory of Performance and Structural Safety for Petroleum Tubular Goods and Equipment Materials, CNPC \\ Tubular Goods Research Institute, Xi’an, China \\ Email: caixuehua@cnpc.com.cn
}

How to cite this paper: Cai, X.H., Li, H.B., Zhang, D.N., Qi, G.Q. and Qi, D.T. (2019) Discussion on the Key Properties of Fiberglass Tubing Used in Oilfield. Journal of Power and Energy Engineering, 7, 64-70. https://doi.org/10.4236/jpee.2019.711008

Received: November 5, 2019

Accepted: November 26, 2019

Published: November 29, 2019

\begin{abstract}
CNPC implements the call of energy conservation and emission reduction, and promotes the application of new energy conservation and emission reduction technologies and new products to achieve production and reduce pollution. As China's oilfields enter the period of high water cut development, corrosion problem and scale formation ordinary steel tubing are becoming more and more serious in oilfield application, which influence and restrict the production and development and bring about energy waste. FRP tubing has been widely used in oil and gas fields because of its excellent corrosion resistance, small friction coefficient and less wear. With the gradual popularization of FRP tubing in oilfields, failure cases also show a growing trend as threaded release, leakage, fracture and so on, which affect the normal production of oilfields. In this paper, a series of key performance properties affecting service performance of high-pressure FRP tubing are tested which took from common failure cases. The key properties of FRP tubing, such as unloading, anti-collapse, short-term failure pressure at high ambient temperature and high ambient temperature axial tension, are tested in the research. The article provides a scientific basis for applicability evaluation of FRP tubing. This research has important significance for energy saving, decreasing pollution and safe operation of tubing pipes. Several suggestions are put forward on material selection and design of FRP tubing.
\end{abstract}

\section{Keywords}

Fiberglass Pipe, Tubing Pipe, Safety Performance Analysis

\section{Preface}

Petrochina carries out the call of energy conservation and emission reduction, and constantly promotes the application of new energy conservation, emission 
reduction technologies and new products to increase production without increasing pollution, improving efficiency and reducing energy consumption. With some oilfields in China entering a high water cut development period, oil recovery are often improved by using water injection, carbon dioxide injection, polymer injection and ASP flooding technology [1] [2]. Generally, water injection technology is used in oil fields to increase formation pressure and liquid production, so as to achieve the purpose of stable production and increase production. Sewage reinjection is often used in water injection process. The reinjected sewage contains a lot of corrosive substances, such as $\mathrm{H}_{2} \mathrm{~S}, \mathrm{SO}_{2}, \mathrm{NaCl}$, $\mathrm{Ca}^{2+}$, etc. The average corrosion rate of these corrosive substances to metals is 1 $1.7 \mathrm{~mm}$ per year. Another situation is that the formation water with high content of $\mathrm{H}_{2} \mathrm{~S}, \mathrm{CO}_{2}, \mathrm{Cl}^{-}$and sulfate reducing bacteria in the natural gas produced by the acid gas field will also cause serious corrosion to the oil pipe, casing and gathering pipeline, and the downhole oil pipe once had corrosion fracture around $2 \mathrm{a}$ [3] [4]. Many measures are adopted to solve the corrosion problems in the oil field, such as adding corrosion inhibitor in the process of water treatment, coating inside and outside the steel pipe, etc. Because these methods can't solve the problem fundamentally, corrosion perforation still occurs in the field of oil field for several months or one or two years, which affects the normal production order of oil field and increases the burden of environment. Fiberglass tubing is a corrosion-resistant material, which has the advantages of superior corrosion-resistant performance, low hydraulic friction coefficient, slow scaling, small friction coefficient, less wear and light weight. According to the simulation test in the laboratory, the service life of GRP is more than 50 years, and the strength retention rate is $75 \%$ after 25 years. The roughness of FRP pipe is 0.0053 , only $2.65 \%$ of seamless steel pipe. The inner wall of FRP pipe is smooth throughout its service life, with small resistance coefficient, saving energy consumption for transportation and improving transportation capacity [5]. The use of FRP pipe can reduce the loss caused by pipeline corrosion, and it can prevent corrosion, improve oil recovery and reduce energy consumption. The field users have brought obvious economic and environmental benefits [6]. However, the quality of FRP tubing products is uneven, and the fact that the actual working conditions are not considered in the selection of oilfield users results in unnecessary energy waste in the process of using such products. With the gradual promotion of FRP tubing in the oil field, the failure cases also show a growing trend. The main failure forms include thread tripping, leakage, fracture, etc., which affect the normal production of the oil field [3]-[9].

Through a series of tests on the index parameters that affect the key performance of FRP tubing, it could be used as a reference for the application of FRP tubing in petroleum industry and oil field. After fully referring to the oil well working condition, pressure grade and main failure form factors of oil field users in actual use of this kind of products, through the screening of key technical indicators, the screw thread on/off performance, high/low temperature short-time failure pressure, high/low temperature axial tension that oil field users are most 
concerned about are determined, and the corresponding test scheme is developed and tested. Based on the analysis of the test results, a series of suggestions are put forward to ensure that FRP tubing can truly play the advantages of low energy consumption, corrosion resistance and environmental friendliness during the use of oil field, and effectively achieve the role of energy conservation and emission reduction.

\section{Typical Failure Cases of FRP Tubing}

\subsection{Thread Releasing}

The main failure reason of thread trip of High Pressure FRP oil pipe is due to processing technology and excessive stress. The thread of FRP oil pipe is usually processed by bonding process or machining process. When the bonding process is adopted, the materials used for the tubing body and thread are different, and the mechanical properties are different, resulting in different strength of the body and thread, while the bonding strength of the thread is significantly lower than that of the tube body, so the thread will trip in use. When the thread is machined, the glass fiber is cut off during turning, reducing the strength of the thread teeth, resulting in the tensile force of FRP thread is small, and thread tripping and fracture appear in the process of field use. In the mechanical production well, the forces of FRP tubing mainly include the self weight of tubing, well fluid buoyancy, fluid column force, friction between plunger and bushing, friction between sucker rod and tubing and friction between fluid column and tubing. When various forces exceed the allowable stress of FRP tubing, FRP tubing will trip due to insufficient strength [3].

\subsection{Pipe Leakage}

Tube leakage is the most common failure mode of FRP tubing. The difference of elastic modulus, Poisson's ratio, elongation and other physical properties between screw thread material and glass fiber and matrix resin will lead to different deformation of screw thread and pipe matrix under the condition of low stress, resulting in leakage at screw thread. With the increase of service time, the leakage is more and more serious. Finally, the thread seal fails [10].

\subsection{Fracture}

After the FRP tubing body is damaged by axial tension or internal pressure tension, the macroscopic failure forms are necking and interlaminar separation along the winding direction. Under the action of external pressure and axial tension, the main failure mode of the tube is buckling failure. The first is the failure of the first layer of the pipe body, and then the overall failure [4] [8].

\section{Key Performance Index Test}

\subsection{Sample Selection}

Two types of high-pressure FRP oil pipes were selected for the test, anhydride 
cured and aramid cured. The specification is DN $65 \mathrm{~mm} \mathrm{PN} 16 \mathrm{MPa}$.

\subsection{Key Performance Test Items}

According to the typical failure mode of FRP, thread trip, pipe leakage and fracture, the test items of loading and unloading, high normal temperature short-time failure pressure and high normal temperature axial tensile performance are determined for research (see Table 1).

\subsubsection{Thread On/Off}

The make-up and break-up torque of FRP tubing is $300 \mathrm{~N} \cdot \mathrm{M}$, the test temperature is room temperature, and the number of make-up and break-up is 10 times. After the thread loading and unloading test, the appearance of the thread is intact, and the thread at the pipe end has no failure damage such as tripping and gluing (see Figure 1(a)). After the test, the thread situation is shown in Figure 1(b).

\subsubsection{Short-Time Failure Pressure at High Temperature/Room Temperature}

Room temperature, $65^{\circ} \mathrm{C}$ and $93^{\circ} \mathrm{C}$ are picked out for short-time failure pressure test of FRP tubing. The short-time water pressure failure pressure results of two different curing methods (acid anhydride curing and amine curing) FRP tubing at different temperatures (room temperature, $65^{\circ} \mathrm{C}$ and $93^{\circ} \mathrm{C}$ ) are all greater than 2.5 times of the nominal pressure. The failure modes of FRP tubing are

Table 1. Key performance test items of high pressure FRP tubing.

\begin{tabular}{ccc}
\hline Test items & Test conditions & Test equipment \\
\hline $\begin{array}{c}\text { Thread on/off } \\
\text { Short time failure } \\
\text { pressure }\end{array}$ & Room temperature & Loading and unloading torque testing machine \\
$\begin{array}{c}\text { Axial tensile } \\
\text { properties }\end{array}$ & Room temperature $165^{\circ} \mathrm{C} \backslash 93^{\circ} \mathrm{C}$ & $\begin{array}{c}\text { Microcomputer controlled electro-hydraulic } \\
\text { servo universal testing machine }\end{array}$ \\
\hline
\end{tabular}

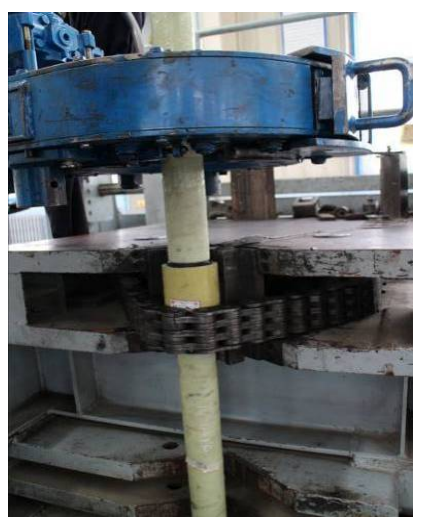

(a)

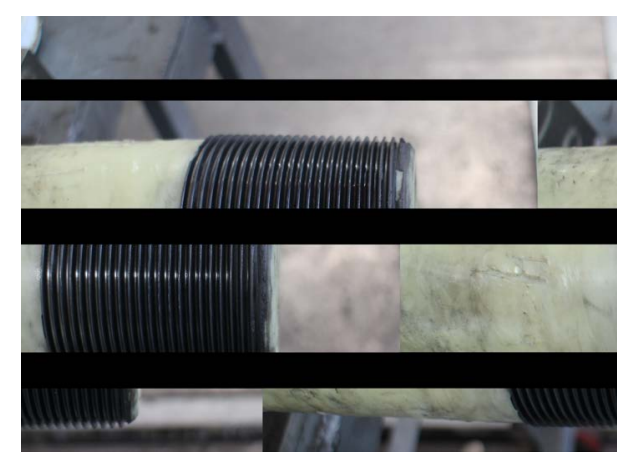

(b)

Figure 1. Thread on/ off test. (a) Test of FRP oil pipe on/off; (b) Thread appearance after 10 times of screwing on and off (no tripping and sticking). 
divided into tube leakage (Figure 2(a)) or joint thread debonding (Figure 2(b)).

\subsubsection{Tensile Properties at High Temperature/Normal Temperature}

The tensile test temperature of FRP tubing is room temperature, $65^{\circ} \mathrm{C}$ and $93^{\circ} \mathrm{C}$. The tensile speed is $10 \mathrm{~mm} / \mathrm{min}$.

Under high temperature condition, the tensile failure load of FRP tubing is almost the same as that at room temperature. After tensile test, all fiberglass tubing samples show failure appearance of thread debonding, and the tube body is intact. See Figure 3(a) for the test process and Figure 3(b) for the thread after the test.

\section{Analysis and Suggestions}

Through the evaluation test of the key performance indexes of two types of FRP tubing solidified with either anhydrides or amines, it can be found that: 1) After 10 times of screwing on and off, the appearance of the pipe end thread is complete without damage, and the randomly selected screwing on and off of FRP tubing can adapt to the oilfield conditions. 2) Under the condition of room

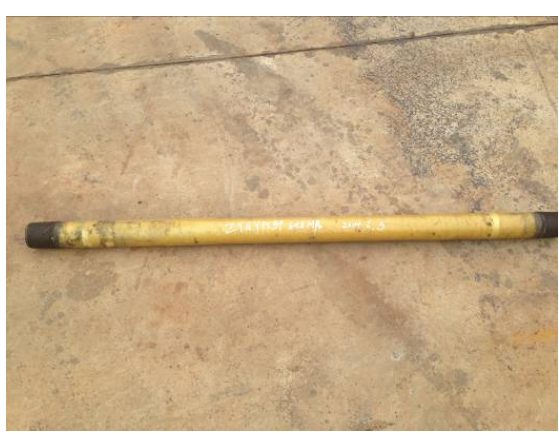

(a)

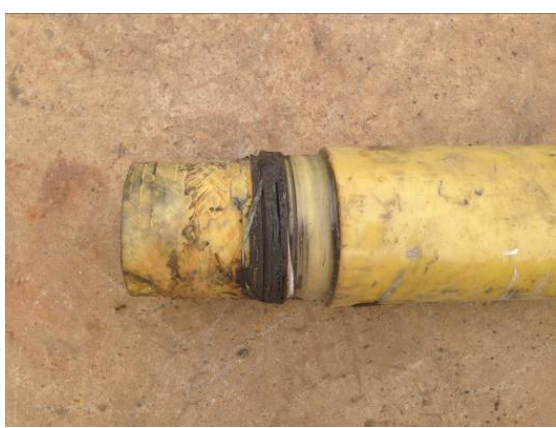

(b)

Figure 2. Short time water pressure failure morphology. (a) Pipe leakage; (b) Joint thread debonding failure.

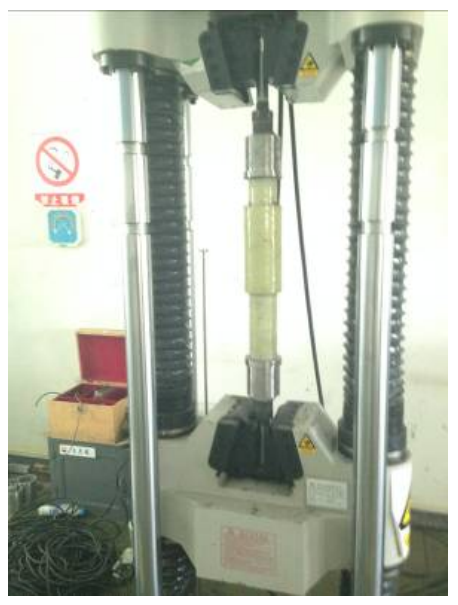

(a)

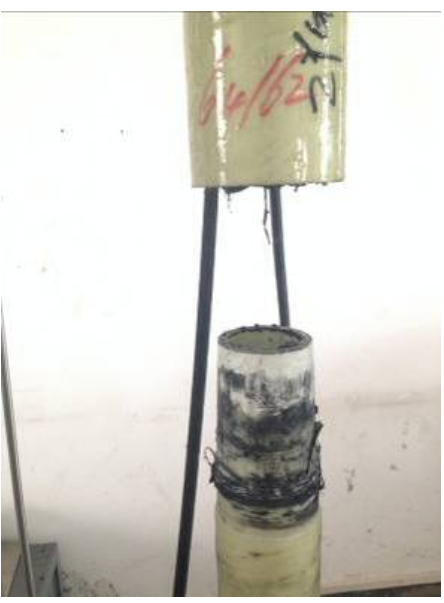

(b)

Figure 3. Axial tensile test. (a) Tensile test process; (b) Typical failure morphology after tensile test (Thread debonding). 
temperature and high temperature, the short-time hydraulic failure pressure of two kinds of GRP tubing selected and tested randomly is greater than 2.5 times of the nominal pressure, which proves that the strength of this batch of products can meet the requirements of different temperature and well depth on site. 3) According to the result analysis of the tensile strength of the screw connection of FRP tubing at high temperature and room temperature, temperature is not the factor affecting the screw connection. Because the axial tensile strength of the screw connection is significantly lower than the tensile strength of the pipe body, the strength of the screw connection is the key index affecting the service performance of FRP tubing. 4) Based on the test results, it is concluded that the oil field users can select suitable FRP tubing according to the temperature requirements of the working conditions. 5) Before using FRP tubing, it is necessary to conduct high and low temperature short-time water pressure failure pressure test, upper and lower shackle test, and tensile test of pipe body and pipe fittings. If they meet the requirements of oil field, they could be applied on site to ensure the safe and long-term stable operation of FRP tubing.

\section{Conclusion}

Based on the test of the key performance affecting the use of FRP tubing, the test results are analyzed. The short-term failure pressure and the tensile resistance of FRP tubing are put forward, which are able to meet the field requirements. It is obvious that the screw connection performance is the key point to ensure the safe operation of FRP tubing. In terms of material selection and design of FRP tubing, the basic performance should reach the standard. It is suggested to strengthen the connection strength and stability of threaded joints in order to ensure the normal use of FRP tubing in the oil field. Moreover, the FRP tubing applied in oilfield should be standardized strictly, and the material selection should fully refer to the oil well conditions and the pressure levels of the actual use of FRP tubing by oilfield users, strengthen the management, improve the evaluation system of FRP tubing production, design, construction, etc., which ensure that FRP tubing can improve the energy utilization efficiency, play the role of energy conservation and reduction the role of pollution.

\section{Conflicts of Interest}

The authors declare no conflicts of interest regarding the publication of this paper.

\section{References}

[1] Zhang, Y.C. (2012) The Technical Characteristics and Application of High-Pressure Fiberglass Underground Pipe. Total Corrosion Control, 26, 49-51.

[2] Jiang, W.G. (2015) Research on Application Technology of High Pressure FRP Pipeline in Oilfield Water Injection. Chemical Enterprise Management, 2, 138.

[3] Ma, L.Z. (2011) Failure Analysis and Countermeasures of FRP Tubing. Oil Field Equipment, 40, 61-64. 
[4] Zhang, Y.C. (2003) Study on High Pressure Fiberglass Pipes Used in Oil Wells. Fiber Composites, 42, 42-44.

[5] Tao, J.D. (2012) Application and Development of Fiber Reinforced Plastic Pipe in Oil \& Gas Field. Petroleum Tubular Goods \& Instruments, 3, 1-4.

[6] Zou, A.L. (2013) Analysis of Problems in the Application of High Pressure FRP Pipeline in Oil Field. Technological Innovation, 15, 75.

[7] Dong, Z.H. (2013) The Summary of Failure Analysis and Test Procedure for FRP Pipe. Guangdong Chemical Industry, 40, 107-108.

[8] Wang, D.L. (2014) Application Status and Prospect of High Pressure Glass Steel Pipes in Oil Fields. New Technology \& New Process, 12, 133-135.

[9] Zhu, H.R. (2017) Research on the Application of FRP in Oil and Gas Pipeline Industry. Technology and Industry across the Straits, 2, 130-131.

[10] Guo, S.W. (2004) Glass Steel Pipe for Oil Field. China Petroleum Industry Press, Beijing. 